\title{
Survival of Stroke Patients According to Hypertension Status in Northern Ethiopia: Seven Years Retrospective Cohort Study
}

This article was published in the following Dove Press journal: Vascular Health and Risk Management

\author{
Zenawi Hagos Gufue $\mathbb{D}^{\prime}$ \\ Naod Firdu Gizaw ${ }^{2}$ \\ Wondimu Ayele ${ }^{2}$ \\ Yared Mamushet Yifru ${ }^{3}$ \\ Nigus Alemu Hailu ${ }^{4}$ \\ Embaba Tekelaye Welesemayat ${ }^{5}$ \\ Etsay Weldekidan Tsegay (iD) ${ }^{6}$ \\ Abadi Hailay Atsbaha (D) ${ }^{\prime}$ \\ Hirut Teame Gebru (ID) \\ 'Department of Public Health, College of \\ Medicine and Health Sciences, Adigrat \\ University, Adigrat, Ethiopia; \\ ${ }^{2}$ Department of Preventive Medicine, \\ School of Public Health, College of \\ Health Sciences, Addis Ababa University, \\ Addis Ababa, Ethiopia; ${ }^{3}$ Department of \\ Neurology, Faculty of Medicine, College \\ of Health Sciences, Addis Ababa \\ University, Addis Ababa, Ethiopia; \\ ${ }^{4}$ Department of Biomedical Sciences, \\ School of Medicine, College of Medicine \\ and Health Sciences, Adigrat University, \\ Adigrat, Ethiopia; ${ }^{5}$ Department of \\ Epidemiology, School of Public Health, \\ College of Health Sciences, Aksum \\ University, Aksum, Ethiopia; \\ ${ }^{6}$ Department of Pharmacy, College of \\ Medicine and Health Sciences, Adigrat \\ University, Adigrat, Ethiopia
}

Background: Globally, stroke appears as a major cause of preventable deaths and disabilities. In Ethiopia, the intra-hospital mortality of stroke is significant; however, epidemiologic data are scarce whether there is a difference in the overall survival time between hypertensive and non-hypertensive adult stroke patients admitted in specialized hospitals. This study was intended to determine the survival of stroke patients according to their hypertension status admitted in Ayder Comprehensive Specialized Hospital, Northern Ethiopia from March 1, 2012, to February 28, 2019.

Methods and Findings: A hospital-based retrospective cohort study was conducted among all cohorts of confirmed first-ever stroke patients admitted in Ayder Comprehensive Specialized Hospital, Northern Ethiopia. Kaplan-Meier survival analysis was applied to estimate the survival probability of hypertensive and non-hypertensive first-ever stroke patients. Cox proportional hazards regression model was used to determine the adjusted hazard ratio of death for each main baseline predictor variable with $95 \% \mathrm{CI}$, and P-value $<0.05$ was used to declare statistical significance. The assumptions of the Cox proportional hazards regression model assessed by the global test, Schoenfeld residuals. There were 503 (323 were hypertensive, 180 Non-hypertensive) confirmed first, ever adult stroke patients, the overall median age of the patients was 65 years, IQR (53-75) years. Seventy-five (14.9\%) of them were dead, with a median survival time of 48 days and $428(85.1 \%)$ of them were censored. At any particular point in time, the hazard of death among hypertensive patients was two times higher than non-hypertensive patients, but this was not found to be a statistically significant (adjusted HR=2.13: 95\% CI 0.66-6.81). Glasgow Coma Scale 3-8 at admission (adjusted $\mathrm{HR}=10.12 ; 95 \%$ CI 2.58-40.68), presence of stroke complications (adjusted HR=7.23; 95\% CI 1.86-28.26) and borderline high total cholesterol level (adjusted $\mathrm{HR}=3.57$; $95 \%$ CI 1.15-11.1) were the only independent predictors of intra-hospital patient mortality.

Conclusion: The overall survival time difference between hypertensive and nonhypertensive first-ever adult stroke patients was not statistically significant. Early identification and treatment of stroke complications, co-morbidities along strict follow-up of comatose patients may improve the intra-hospital survival of stroke patients, and we also recommend community-based studies using a large sample size.

Keywords: hypertension, stroke, cox regression, predictors of survival, Ethiopia

\section{Introduction}

In the previous studies, there were conflicting results in the independent survival effect of pre-stroke hypertension among adult stroke patients admitted in different 
specialized hospitals ${ }^{1}$ and community-based stroke registries. ${ }^{2}$ Even though the exact emergency burden of stroke in Ethiopia is not known, it has been estimated to be increasing and stroke accounts for $2.5 \%$ of all hospital admissions and $13.7 \%$ of medical admissions. ${ }^{3}$ According to the latest data published in 2017, stroke deaths in Ethiopia reached 39,571 or $6.23 \%$ of total deaths. The age-adjusted death rate of stroke accounts for 89.82 per 100,000 population. ${ }^{4}$

In Sub-Saharan Africa including Ethiopia, there are no methodologically robust stroke studies, ${ }^{5}$ and the previously conducted stroke studies in the African Continent and particularly in Ethiopia mainly focused on a descriptive summary of types, sub-types of stroke, risk profiles of patients and magnitude of risk factors. According to the latest global burden of disease report, globally there were 11.9 million new stroke cases, almost 1 in 8 deaths worldwide $(12 \%, 6.5$ million deaths) were attributable due to stroke, whereby stroke takes a life every five seconds, making stroke the second leading global cause of death. 6,7

With the growing worldwide burden of stroke, someone in the world will have a stroke every two seconds. ${ }^{8}$ In the absence of a significant global public health response stroke is projected to rise to 23 million new cases and 7.8 million deaths per year by the end of $2030 .^{9}$ To the best level of our knowledge (unlike western countries), we did not get studies conducted in Ethiopia on determining whether there is a difference in the survival time between hypertensive and non-hypertensive first-ever stroke patients. This study was intended to determine the survival of stroke patients according to their hypertension status admitted to Ayder Comprehensive Specialized Hospital, Northern Ethiopia.

\section{Materials and Methods}

The study was conducted in Ayder Comprehensive Specialized Hospital (ACSH), Mekelle city, Tigray Regional State, Northern Ethiopia. ACSH is a government-owned teaching hospital and research center in Northern Ethiopia, rendering its referral and specialized medical services to more than 9 million people in its catchment areas of Tigray, Afar, and North-Eastern parts of the Amhara Regional States, and Eritrean refugees. ${ }^{10}$ All patients presenting with acute neurological symptoms are initially admitted at the emergency department of the hospital and they will be investigated with Computerized Tomography (CT) scan or Magnetic Resonance Imaging
(MRI). Severe cases admitted to the medical wards, and adult intensive care units, but the hospital has no stroke center and registry. The study period was seven years period from March 1, 2012 (when the hospital started using CT scan/MRI machine) to February 28, 2019, and the data extraction period was carried out from January 1 to March 31, 2019.

\section{Study Design}

A hospital-based retrospective cohort study was conducted among confirmed first-ever adult stroke patients admitted to the emergency rooms, medical wards, and adult intensive care units of the hospital with the primary diagnosis of stroke as per the World Health Organization (WHO) clinical case definition.

\section{Sample Size Determination and Sampling Technique}

The sample size was determined using two population proportion formula using Epi info version 7.2.2.6 software, ${ }^{11}$ taking hypertension status of adult stroke patients as a primary exposure variable and with the assumptions of two-sided significance level $(\alpha=5 \%)$, power $(1-\beta)=80 \%, 95 \%$ confidence level, the ratio of nonexposed to exposed (R) 1:1. Accordingly, the sample size was calculated with the assumptions of percent of exposed (hypertensive) with outcome $=59.2 \%,{ }^{12}$ percent of nonexposed (non-hypertensive) with outcome $=40.8 \%{ }^{12}$ and an adjustment made for irretrievable patient medical records by taking $15 \%$. The final sample size required to get a statistically meaningful difference between the two groups was 298. Since the total numbers of first-ever adult stroke cases were manageable (503 patients) and we want to increase, the power of the study all confirmed adult stroke cases were included in the study.

\section{Data Collection Instrument and Process}

Data were collected using a pre-tested data abstraction checklist, developed after reviewing different works of literature, ${ }^{13}$ and previous similar studies, ${ }^{5,14,15}$ then organized according to the objectives of the study. The checklist was prepared in English and for the ease of data abstraction process; it contained four parts, sociodemographics of stroke patients, antecedent risk factors of stroke, neurological factors, and acute stroke event factors. Five experienced data collectors and two supervisors were involved in the data collection process. 


\section{Operational Definitions \\ Definition of the Exposure Variable}

Exposed group (Hypertensive patients): If a patient was taking antihypertensive medications before admission, history of being diagnosed as hypertensive by a health professional before the onset of stroke, documented blood pressure of $\geq 140 / 90 \mathrm{mmHg}$ before the onset of stroke or persisting after the acute phase of the stroke. Non-exposed group (Non-hypertensive patients): It was defined as having a blood pressure reading of $<140 / 90 \mathrm{mmHg}$ before or after the onset of stroke. ${ }^{13}$

\section{Definition of the Outcome Variable}

Adult Stroke death: It was defined as recorded stroke death within the follow-up time occurring among first-ever adult stroke patients aged 18 years and above and ascertainment of death was from death records on the patient's medical record. ${ }^{13}$ Censored: Those subjects who were discharged against medical advice, discharged with significant neurologic deficit, death other than stroke (accident or any cause not related to stroke), referred to other health facilities or event free until the end of the study whichever occurred first were considered as censored. ${ }^{13}$

\section{Definition of the Covariates}

Diabetes mellitus: It was defined as when the patient was taking any anti-diabetic medication or when a random blood sugar level of $\geq 200 \mathrm{mg} / \mathrm{dL}$ or two consecutive fasting venous plasma glucose levels of $\geq 126 \mathrm{mg} / \mathrm{dL}$ which persists beyond the acute phase of stroke (after one week of hospital admission). ${ }^{16}$

\section{Dyslipidemia}

It was defined as when the patient was taking lipidlowering medications or a total cholesterol level of $\geq$ $240 \mathrm{mg} / \mathrm{dL} .{ }^{17}$ Event (failure): All-cause intrahospital adult stroke death from all types of stroke which occurred within 90 days of admission. ${ }^{1}$ First-ever stroke: A stroke that occurred in persons who never had a stroke before. ${ }^{13}$

\section{Glasgow Coma Scale (GCS)}

is a 15-point neurological scale that aims to reliably and objectively record the level of consciousness of a patient (coma severity) presenting with neurologic symptoms. Interpretation of GCS is based on the score; GCS score of 13-15 (Mild brain injury), GCS score of 9-12 (Moderate brain injury), GCS score of 3-8 (Severe brain injury). ${ }^{18}$

\section{Study Variables}

The outcome variable is follow-up time in days after admission to death, whereas the independent variable is hypertension status as hypertensive and non-hypertensive. The covariates of interest were socio-demographic characteristics of adult stroke patients, antecedent risk factors of stroke, neurologic factors, stroke event factors.

\section{Data Processing, Management, and Analysis}

The collected data were coded and checked for its clarity, consistency, and completeness up to the end of each data collection period and Epi info Version 7.2.2.6 ${ }^{11}$ was used for data entry. The entered data was exported to STATA version 14.0. ${ }^{19}$ Descriptive statistics of numeric variables presented in medians with interquartile range (IQR), categorical variables presented using frequency and percentages, and the outcomes of each patient dichotomized into censored or dead.

The person-days of follow-up computed from admission to death, loss to follow-up, or the end of the study which occurred first. Stroke mortality rate calculated by dividing the number of deaths among first-ever stroke cases occurring to person-days of follow up. The cumulative survival rate after admission among first-ever stroke cases was estimated using the Kaplan Meier survival analysis method on day 2 , day 7 , day 10 , day 14 , and day 28 after admission to the hospital.

The observed difference in survival time between hypertensive and non-hypertensive first ever-adult stroke patients compared using the Log rank test. To assess the association among baseline variables and patient survival two strategies used, first each baseline variable that did not violate the assumptions of the Cox proportional hazards regression model entered into a separate Cox regression model. Second, a multivariable Cox proportional hazards regression model was fitted containing clinically important predictors and those variables, which had $\mathrm{P}<0.25$ in the bivariate model. ${ }^{20}$

The assumptions of the Cox proportional hazard regression model checked by the following procedures: $\log (-\log (\mathrm{St})$ plots, Schoenfeld residual plots, and by regressing Schoenfeld residuals against time to test for independence between time and residuals. The covariates, which violate the assumptions of the Cox proportional hazards regression model, were not included in the model and missing data, handled by simple deletion from 
the bivariate and multivariable analysis. The summary measures of estimated Crude Hazard Ratio (CHR) and Adjusted Hazard Ratio (AHR) with a 95\% confidence interval for the survival rate among first-ever adult stroke patients estimated. P-value $<0.05$ used to declare statistical significance and goodness of fit of the model assessed by the Cox-Snell residuals plot.

\section{Results}

\section{Socio-Demographic Characteristics of Patients}

Between March 1, 2012, and February 28, 2019, there were 503 cohorts of confirmed first-ever adult stroke patients admitted in Ayder Comprehensive Specialized Hospital, among these $323(64.2 \%)$ of them were hypertensive and $180(35.8 \%)$ of them were non-hypertensive adult stroke patients. The power of the study was $100 \%$ and the overall median age was 65 years with IQR (53-75) years. According to their exposure status, hypertensive patients' median age was 65 years with IQR (53-75) years, among non-hypertensive patients their median age was 68 years and IQR (54-76) years.

Concerning sex distribution 252 (50.1\%) of them were male patients and 285 (56.7\%) of the patients were urban residents. Concerning their educational status, 500 (99.4\%) patients' educational status was not recorded. Similarly, the marital and occupational statuses of the patients were unrecorded among 481 (95.6\%) and 492 (97.8\%) patients' medical records respectively (Table 1).

\section{Antecedent Risk Factors of Stroke}

Among the $323(64.2 \%)$ hypertensive adult stroke patients admitted, 275 (85.1\%) of them were diagnosed before admission and 48 (14.9\%) of them were diagnosed after hospital admission. Among those hypertensive patients diagnosed before admission, 199 (72.4\%) of them were not adherent to their respective antihypertensive medications and the median time since when patients were told to be hypertensive was 2 years with IQR (1-5) years.

Table I Socio-Demographic Characteristics of First Ever-Adult Stroke Patients Admitted in Ayder Comprehensive Specialized Hospital, Northern Ethiopia, 2012-2019 ( $n=503)$

\begin{tabular}{|c|c|c|c|c|c|}
\hline \multicolumn{2}{|c|}{ Baseline Variables } & \multicolumn{2}{|c|}{ Exposure Category } & \multirow{3}{*}{$\begin{array}{l}\text { Total } \\
\text { Frequency (\%) }\end{array}$} & \multirow[t]{3}{*}{ P-value $\left(\chi^{2}\right)$} \\
\hline & & \multirow{2}{*}{$\begin{array}{l}\text { Hypertensive } \\
\text { Frequency (\%) }\end{array}$} & \multirow{2}{*}{$\begin{array}{l}\text { Non-Hypertensive } \\
\text { Frequency (\%) }\end{array}$} & & \\
\hline & & & & & \\
\hline Age (years) & $\begin{array}{l}<45 \\
45-54 \\
55-64 \\
65-74 \\
75-84 \\
\geq 85\end{array}$ & $\begin{array}{l}44(8.7) \\
40(8.0) \\
68(I 3.5) \\
87(I 7.3) \\
64(I 2.7) \\
20(3.9)\end{array}$ & $\begin{array}{l}30(6.0) \\
14(2.8) \\
31(6.2) \\
45(8.9) \\
38(7.6) \\
22(4.4)\end{array}$ & $\begin{array}{l}74(14.7) \\
54(10.8) \\
99(19.7) \\
132(26.2) \\
102(20.3) \\
42(8.3)\end{array}$ & 0.1 \\
\hline Sex & $\begin{array}{l}\text { Female } \\
\text { Male }\end{array}$ & $\begin{array}{l}162(32.2) \\
161(32)\end{array}$ & $\begin{array}{l}89(17.7) \\
91(18.1)\end{array}$ & $\begin{array}{l}251(49.9) \\
252(50.1)\end{array}$ & 0.88 \\
\hline Religion & $\begin{array}{l}\text { Orthodox } \\
\text { Muslim } \\
\text { Catholic } \\
\text { Unrecorded }^{\text {a }}\end{array}$ & $\begin{array}{l}96(19.1) \\
29(5.8) \\
3(0.6) \\
195(38.8)\end{array}$ & $\begin{array}{l}62(12.3) \\
15(2.9) \\
0 \\
103(20.5)\end{array}$ & $\begin{array}{l}\mid 58(31.4) \\
44(8.7) \\
3(0.6) \\
298(59.3)\end{array}$ & 0.43 \\
\hline Residence & $\begin{array}{l}\text { Urban } \\
\text { Rural } \\
\text { Unrecorded }^{a}\end{array}$ & $\begin{array}{l}199(39.6) \\
114(22.7) \\
10(1.9)\end{array}$ & $\begin{array}{l}86(17.1) \\
88(17.5) \\
6(1.2)\end{array}$ & $\begin{array}{l}285(56.7) \\
202(40.2) \\
16(3.1)\end{array}$ & $0.01 *$ \\
\hline Ethnicity & $\begin{array}{l}\text { Tigrian } \\
\text { Afar } \\
\text { Others }^{\ddagger} \\
\text { Unrecorded }^{\text {a }}\end{array}$ & $\begin{array}{l}28 \mid(55.9) \\
12(2.4) \\
8(1.6) \\
22(4.4)\end{array}$ & $\begin{array}{l}159(31.6) \\
7(1.4) \\
5(0.9) \\
9(1.8)\end{array}$ & $\begin{array}{l}440(87.5) \\
19(3.8) \\
13(2.5) \\
31(6.2)\end{array}$ & 0.85 \\
\hline
\end{tabular}

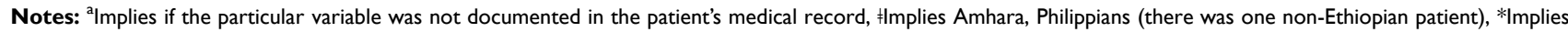
that patients were not comparable based on their place of residence (urban/rural). 


\section{Neurological Factors}

Ischemic stroke was the most common type of stroke identified among 285 (56.6\%) of stroke patients and among those known sub-types of ischemic stroke, Cardioembolic stroke was the most common sub-type identified among $69(24.2 \%)$ ischemic stroke patients. The most frequent clinical presentations seen among first-ever adult stroke patients were hemiparesis and speech disturbances found among 397 (78.9\%) and 227 (45.1\%) patients respectively. Concerning the patient's level of consciousness during hospital arrival 227 (45.1\%) patients had a mild level of unconsciousness, GCS score of 13-15 (Table 2).

The median duration from the onset of stroke symptoms to hospital arrival for the cohort was 24 hours with
IQR (12-72) hours. According to their exposure status, the median duration from onset of stroke symptoms to hospital arrival for hypertensive patients was 24 hours, IQR (12-72) hours and for non-hypertensive patients was 48 hours, IQR (24-96) hours. Concerning the length of stay in the hospital 203 (40.4\%) of the patients stayed up to two weeks and 128 (25.4\%) patients stayed in the hospital for more than two weeks. Two hundred thirty-six $(46.9 \%)$ of the patients develop at least one neuro-medical stroke complications, from these the top three complications were aspiration pneumonia, increased intracranial pressure (ICP) and urinary tract infection (UTI) which occurred among 183 (36.4\%), 58 $(11.5 \%)$ and $38(7.6 \%)$ of stroke patients respectively (Table 3).

Table 2 Neurological Characteristics of First-Ever Adult Stroke Patients Admitted in Ayder Comprehensive Specialized Hospital, Northern Ethiopia, 2012-2019

\begin{tabular}{|c|c|c|c|c|c|}
\hline \multirow[t]{3}{*}{ Patient Profile } & \multirow[t]{3}{*}{ Response } & \multicolumn{2}{|c|}{ Exposure Category } & \multirow[t]{2}{*}{ Total } & \multirow{3}{*}{$\begin{array}{l}\text { P-value } \\
\left(\alpha^{2}\right)\end{array}$} \\
\hline & & Hypertensive & $\begin{array}{l}\text { Non- } \\
\text { Hypertensive }\end{array}$ & & \\
\hline & & $\begin{array}{l}\text { Frequency } \\
\text { (\%) }\end{array}$ & $\begin{array}{l}\text { Frequency } \\
\text { (\%) }\end{array}$ & $\begin{array}{l}\text { Frequency } \\
\text { (\%) }\end{array}$ & \\
\hline Type of stroke identified $(n=503)$. & $\begin{array}{l}\text { IS } \\
\text { HS } \\
\text { SAH }\end{array}$ & $\begin{array}{l}137(27.2) \\
180(35.8) \\
6(1.2)\end{array}$ & $\begin{array}{l}148(29.4) \\
29(5.8) \\
3(0.6)\end{array}$ & $\begin{array}{l}285(56.6) \\
209(4 I .6) \\
9(1.8)\end{array}$ & $<0.00 I^{*}$ \\
\hline Etiologic subtypes of Ischemic stroke $(n=285)$ & $\begin{array}{l}\text { Cardio- } \\
\text { embolic } \\
\text { LAA } \\
\text { SAO } \\
\text { Unclassified }{ }^{\text {a }}\end{array}$ & $\begin{array}{l}30(10.5) \\
8(2.8) \\
33(11.5) \\
66(23.2)\end{array}$ & $\begin{array}{l}39(13.7) \\
13(4.6) \\
29(10.2) \\
67(23.5)\end{array}$ & $\begin{array}{l}69(24.2) \\
21(7.4) \\
62(21.7) \\
133(46.7)\end{array}$ & 0.53 \\
\hline Causes of HS $(n=209)$ & $\begin{array}{l}\text { Hypertension } \\
\text { Others }{ }^{\S} \\
\text { Unclassified }{ }^{b}\end{array}$ & $\begin{array}{l}177(84.6) \\
1(0.5) \\
2(1)\end{array}$ & $\begin{array}{l}\mathrm{I}(0.5) \\
4(2) \\
24(1 \mathrm{I} .4)\end{array}$ & $\begin{array}{l}178(85.1) \\
5(2.5) \\
26(12.4)\end{array}$ & $<0.00 I^{*}$ \\
\hline $\begin{array}{l}\text { Clinical presentation at admission (multiple clinical presentations } \\
\text { were possible) }(n=503) \text {. }\end{array}$ & $\begin{array}{l}\text { Coma } \\
\text { Aphasia } \\
\text { Hemiparesis } \\
\text { Hemiplegia } \\
\text { CN palsy } \\
\text { Headache } \\
\text { Vomiting } \\
\text { Others } \#\end{array}$ & $\begin{array}{l}85(16.9) \\
145(28.8) \\
253(50.3) \\
24(4.8) \\
44(8.7) \\
127(25.2) \\
125(24.8) \\
22(4.4)\end{array}$ & $\begin{array}{l}44(8.7) \\
82(16.3) \\
144(28.6) \\
15(3) \\
28(5.6) \\
47(9.3) \\
37(7.4) \\
10(2)\end{array}$ & $\begin{array}{l}129(25.6) \\
227(45.1) \\
397(78.9) \\
39(7.8) \\
72(14.3) \\
174(34.5) \\
162(32.2) \\
32(6.4)\end{array}$ & $\begin{array}{l}0.65 \\
0.89 \\
0.67 \\
0.72 \\
0.55 \\
0.3 \\
0.19 \\
0.56\end{array}$ \\
\hline GCS at admission $(n=503)$. & $\begin{array}{l}3-8 \\
9-12 \\
13-15\end{array}$ & $\begin{array}{l}61(12.1) \\
I I I(22.1) \\
151(30)\end{array}$ & $\begin{array}{l}32(6.4) \\
72(14.3) \\
76(15.1)\end{array}$ & $\begin{array}{l}93(18.5) \\
183(36.4) \\
227(45.1)\end{array}$ & 0.45 \\
\hline
\end{tabular}

Notes: andicates for ischemic stroke subtypes not classified according to Trial of Org 10, I72 in Acute Stroke Treatment classification, 'Indicates for those causes of hemorrhagic stroke which were not further classified, Indicates for Amyloid Angiopathy, Vascular aneurism, and anticoagulant related causes, "Indicates vertigo, abnormal body movement, fecal and urinary incontinences, *Implies that patients were not comparable based on their type of stroke and causes of Hemorrhagic stroke using Fisher's exact test. Abbreviations: CN, cranial nerve; GCS, Glasgow Coma Scale; HS, hemorrhagic stroke; IS, ischemic stroke; LAA, large artery atherosclerosis; SAH, sub-arachnoid hemorrhage; SAO, small artery occlusion. 
Table 3 Stroke Event Factors ${ }^{\dagger}$ at Admission Among First-Ever Adult Stroke Patients Admitted in Ayder Comprehensive Specialized Hospital, Northern Ethiopia, 2012-2019

\begin{tabular}{|c|c|c|c|c|c|}
\hline \multirow[t]{3}{*}{ Patient Profile } & \multirow[t]{3}{*}{ Categories } & \multicolumn{2}{|c|}{ Exposure Category } & \multirow[t]{2}{*}{ Total } & \multirow{3}{*}{$\begin{array}{l}\text { P-value } \\
\left(\chi^{2}\right)\end{array}$} \\
\hline & & Hypertensive & $\begin{array}{l}\text { Non- } \\
\text { Hypertensive }\end{array}$ & & \\
\hline & & $\begin{array}{l}\text { Frequency } \\
\text { (\%) }\end{array}$ & $\begin{array}{l}\text { Frequency } \\
\text { (\%) }\end{array}$ & $\begin{array}{l}\text { Frequency } \\
\text { (\%) }\end{array}$ & \\
\hline Time from stroke onset to hospital arrival (in hours) & $\begin{array}{l}>6 \\
\text { Others }{ }^{\mathrm{a}} \\
\text { Total }\end{array}$ & $\begin{array}{l}308(61.2) \\
15(3) \\
323(64.2)\end{array}$ & $\begin{array}{l}175(34.8) \\
5(1) \\
180(35.8)\end{array}$ & $\begin{array}{l}483(96) \\
20(4) \\
503(100)\end{array}$ & 0.31 \\
\hline Timing of brain imaging done (in hours) & $\begin{array}{l}\leq 3 \\
>3 \\
\text { Total }\end{array}$ & $\begin{array}{l}0 \\
323(64.2) \\
323(64.2)\end{array}$ & $\begin{array}{l}I(0.2) \\
I 79(35.6) \\
I 80(35.8)\end{array}$ & $\begin{array}{l}\mathrm{I}(0.2) \\
502(99.8) \\
503(100)\end{array}$ & 0.18 \\
\hline Length of hospital stay (in days) & $\begin{array}{l}1-7 \\
7-14 \\
\geq 14 \\
\text { Total }\end{array}$ & $\begin{array}{l}117(23.3) \\
125(24.9) \\
81(16.1) \\
323(64.3)\end{array}$ & $\begin{array}{l}55(10.9) \\
78(15.5) \\
47(9.3) \\
180(35.7)\end{array}$ & $\begin{array}{l}172(34.2) \\
203(40.4) \\
128(25.4) \\
503(100)\end{array}$ & 0.42 \\
\hline Presence of stroke Complications & $\begin{array}{l}\text { Yes } \\
\text { No } \\
\text { Total }\end{array}$ & $\begin{array}{l}\mid 52(30.2) \\
|7|(34) \\
323(64.2)\end{array}$ & $\begin{array}{l}84(16.7) \\
96(19.1) \\
180(35.8)\end{array}$ & $\begin{array}{l}236(46.9) \\
267(53.1) \\
503(100)\end{array}$ & 0.93 \\
\hline $\begin{array}{l}\text { Types of stroke complications detected (a patient can have } \\
\text { more than one complication) }\end{array}$ & $\begin{array}{l}\text { Aspiration } \\
\text { Pneumonia } \\
\text { Increased ICP } \\
\text { UTI } \\
\text { DVT } \\
\text { Seizure } \\
\text { Others }{ }^{\#}\end{array}$ & $\begin{array}{l}115(22.9) \\
45(8.9) \\
25(5) \\
10(2) \\
18(3.6) \\
15(3)\end{array}$ & $\begin{array}{l}68(13.5) \\
13(2.6) \\
13(2.6) \\
9(1.8) \\
7(1.4) \\
4(0.8)\end{array}$ & $\begin{array}{l}183(36.4) \\
58(11.5) \\
38(7.6) \\
19(3.8) \\
25(5) \\
19(3.8)\end{array}$ & $\begin{array}{l}0.63 \\
0.24 \\
0.83 \\
0.28 \\
0.41 \\
0.55\end{array}$ \\
\hline Platelet count (cells $/ \mathrm{mm}^{3}$ ) & $\begin{array}{l}<150,000 \\
150-450,000 \\
>450,000 \\
\text { Total }\end{array}$ & $\begin{array}{l}37(7.4) \\
269(53.5) \\
17(3.3) \\
323(64.2)\end{array}$ & $\begin{array}{l}24(4.8) \\
140(27.8) \\
16(3.2) \\
180(35.8)\end{array}$ & $\begin{array}{l}61(12.13) \\
409(81.31) \\
33(6.56) \\
503(100)\end{array}$ & 0.21 \\
\hline Serum creatinine $(m g / d L)(n=49 l)$ & $\begin{array}{l}\leq 1.6 \\
>1.6 \\
\text { Total }\end{array}$ & $\begin{array}{l}296(60.3) \\
20(4.1) \\
316(64.4)\end{array}$ & $\begin{array}{l}I 64(33.4) \\
I I(2.2) \\
I 75(35.6)\end{array}$ & $\begin{array}{l}460(93.7) \\
31(6.3) \\
491(100)\end{array}$ & 0.99 \\
\hline
\end{tabular}

Notes: ${ }^{\dagger}$ Hypertensive and non-hypertensive adult stroke patients were comparable by all of the acute stroke event factors (P-value was non-significant in all of the event factors), "Includes those patients who present to the hospital within 3 hours, 3 to 4.5 hours and 4.5 to 6 hours of stroke symptoms onset, ${ }^{\#}$ Includes Gastro-intestinal bleeding, Myocardial infarction, hypokalemia, hypocalcemia, and bedsore.

Abbreviations: DVT, deep venous thrombosis; ICP, increased intracranial pressure; UTI, urinary tract infection.

\section{Survival Analysis}

The total person-days of observation for the entire cohort was 5281 person-days (3380 person-days for hypertensive patients and 1901 person-days for non-hypertensive patients), with a median follow-up time of 8 days and IQR (5-14) days. According to exposure status, the median follow-up time for hypertensive patients was 8 days with IQR (5-14) days and the median follow up time for nonhypertensive patients was 9 days with IQR (5-14) days.
The overall median survival time among first everadult stroke patients was 48 days (95\% CI; 48-not reachable), the median survival time among hypertensive patients was 48 days (95\% CI 48-not reachable), the median survival time for non-hypertensive patients was not reachable, but $25 \%$ of them survive up to 25 days of admission. The median time of death for the entire cohort was four days with IQR (1-7) days. Among hypertensive patients, the median time of death was four days with IQR (1-7) days after admission. 
Table 4 Kaplan - Meier Estimate of Survivor Function Among First Ever-Adult Stroke Patients Admitted in Ayder Comprehensive Specialized Hospital, Northern Ethiopia, 2012-19

\begin{tabular}{|c|c|c|c|c|c|c|}
\hline Exposure Status & Time (Days) & Beginning Total & Fail & Survivor Function & Std. Error & $95 \% \mathrm{Cl}$ \\
\hline \multirow[t]{5}{*}{ Hypertensive } & 2 & 301 & 17 & 0.95 & 0.01 & $0.92,0.97$ \\
\hline & 7 & 206 & 39 & 0.87 & 0.02 & $0.82,0.90$ \\
\hline & 10 & 136 & 6 & 0.83 & 0.02 & $0.78,0.87$ \\
\hline & 14 & 81 & 3 & 0.81 & 0.03 & $0.75,0.86$ \\
\hline & 28 & 14 & 1 & 0.80 & 0.03 & $0.73,0.85$ \\
\hline \multirow[t]{5}{*}{ Non-hypertensive } & 2 & 163 & 14 & 0.92 & 0.02 & $0.87,0.95$ \\
\hline & 7 & 125 & 18 & 0.89 & 0.02 & $0.84,0.94$ \\
\hline & 10 & 78 & I & 0.89 & 0.03 & $0.83,0.93$ \\
\hline & 14 & 47 & 2 & 0.85 & 0.03 & $0.76,0.91$ \\
\hline & 28 & 9 & 3 & 0.73 & 0.08 & $0.55,0.85$ \\
\hline
\end{tabular}

The median time of death for non-hypertensive adult stroke patients was two days with IQR (1-7.5) days and the overall 30-day case fatality rate was $15 \%$ (74/489), among hypertensive $15.97 \%$ (50/313) and 13.64\% (24/176) among non-hypertensive adult stroke patients. The cumulative survival probability for hypertensive adult stroke patients up to the end of the first week was $87 \%(95 \%$ CI $82-90)$ and by the end of the first month was $80 \%$ (95\% CI 73-85). Similarly, among non-hypertensive patients was $89 \%(95 \%$ CI 84-94) and 73\% (95\% CI 55-85) respectively (Table 4).

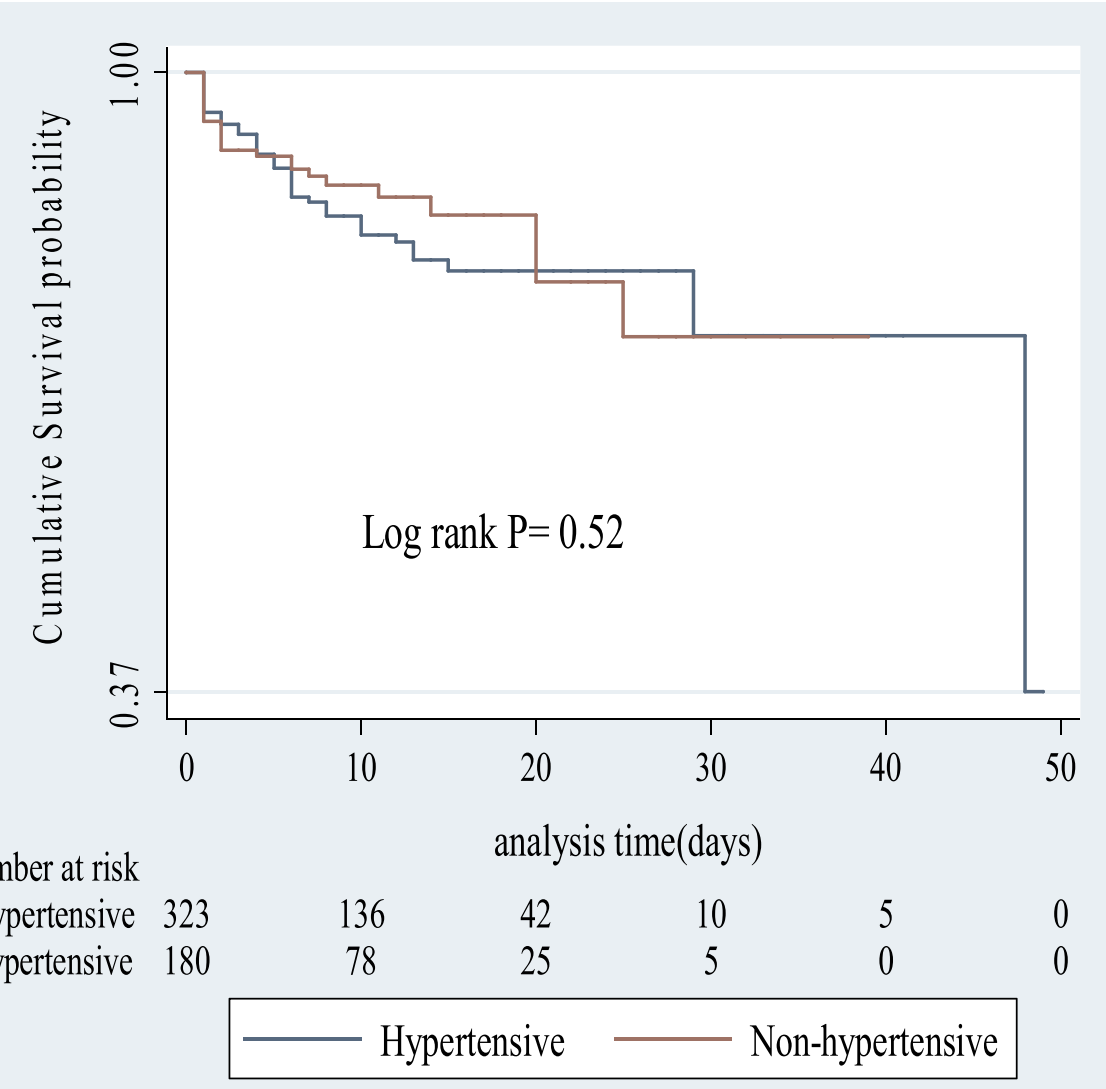

Figure I Kaplan-Meier survival curve based on exposure status among first ever-adult stroke patients admitted in Ayder comprehensive specialized hospital, Northern Ethiopia, 2012-2019. 
A comparison of the survival curves between hypertensive and non-hypertensive adult stroke patients by Kaplan-Meier survival analysis revealed that there was no statistically significant difference in the overall survival time (Log rank test $=0.42, d f=1, \mathrm{P}=0.52)$ (Figure 1). There is a statistically significant difference in the overall survival time among patients with different GCS score $($ Log rank test $=139.59, \mathrm{df}=2, \mathrm{P}<0.0001)$ (Figure 2). Similarly, there was a statistically significant (Log rank test $42.21, \mathrm{df}=1, \mathrm{P}<0.0001$ ) difference in the survival probability of patients who developed any of the stroke complications as compared to their counterparts who did not develop any stroke complications (Figure 3).

Adult stroke patients who had borderline high cholesterol levels had lower cumulative survival probability as compared to those who had normal total cholesterol levels (Log rank test $=7.19, \mathrm{df}=2, \mathrm{P}=0.028$ ) (Figure 4). There was also a statistically significant difference in their cumulative survival probability among the following groups of patients; urban and rural residents, Type of stroke identified, and causes of hemorrhagic stroke.

The multivariable Cox proportional hazards regression model shows that at any particular point in time the hazard of death among hypertensive adult stroke patients was two times higher $(\mathrm{AHR}=2.13$; 95\% CI $0.66-6.81)$ than non- hypertensive adult stroke patients by controlling the effect of other variables, but this finding was not statistically significant. The hazard of death at any particular point in time among those adult stroke patients admitted with GCS score of 3-8 had $10.12(\mathrm{AHR}=10.12 ; 95 \%$ CI 2.58-40.68) times the higher hazard of death as compared to those who had a GCS score of 13-15, by controlling the effect of other variables (Table 5).

\section{Discussions}

This study provided the first evidence on the survival of adult stroke patients and the predictors of mortality among Ethiopian first ever-adult stroke patients. There were 75 deaths $(14.9 \%)$ over the seven years (with a one-month case fatality rate of $15 \%$ ) out of 503 first ever-adult stroke patients. In our study, the mortality from a stroke at day 10 and 28 was 14.8 and $23.1 \%$ as compared to the study conducted in Kenya, ${ }^{21}$ the overall mortality rates were 18.4 and $26.7 \%$ respectively.

We found a non-significant difference in the overall survival time between hypertensive and non-hypertensive first ever-adult stroke patients, despite having two times the higher hazard of death among hypertensive patients. In agreement with our study, a study conducted in South London $^{2}$ found that pre-stroke hypertension was not an independent predictor of patient survival and hypertensive

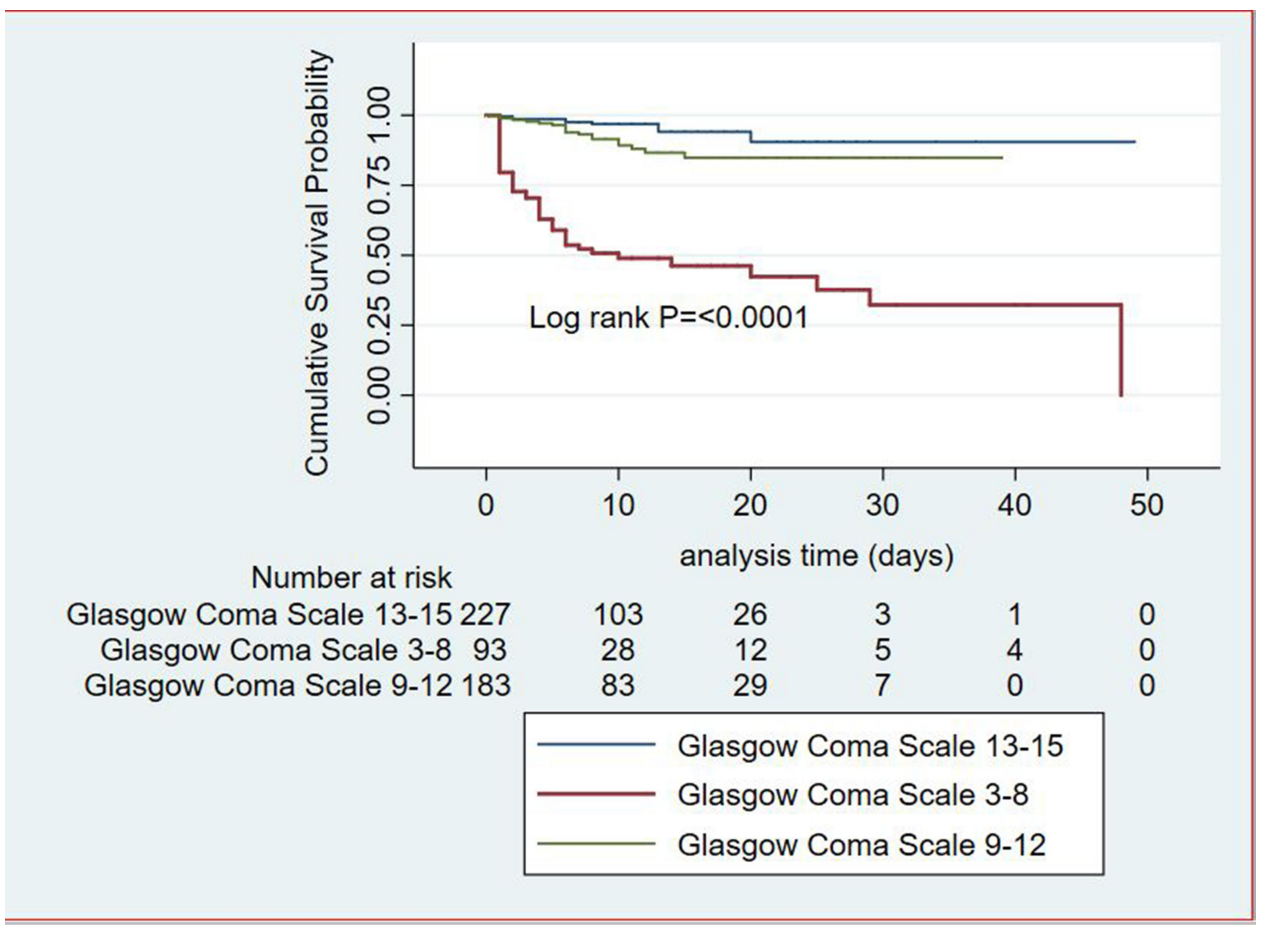

Figure 2 Kaplan-Meier survival curve based on admission Glasgow Coma Scale among first ever-adult stroke patients admitted in Ayder comprehensive specialized hospital, Northern Ethiopia, 2012-2019. 


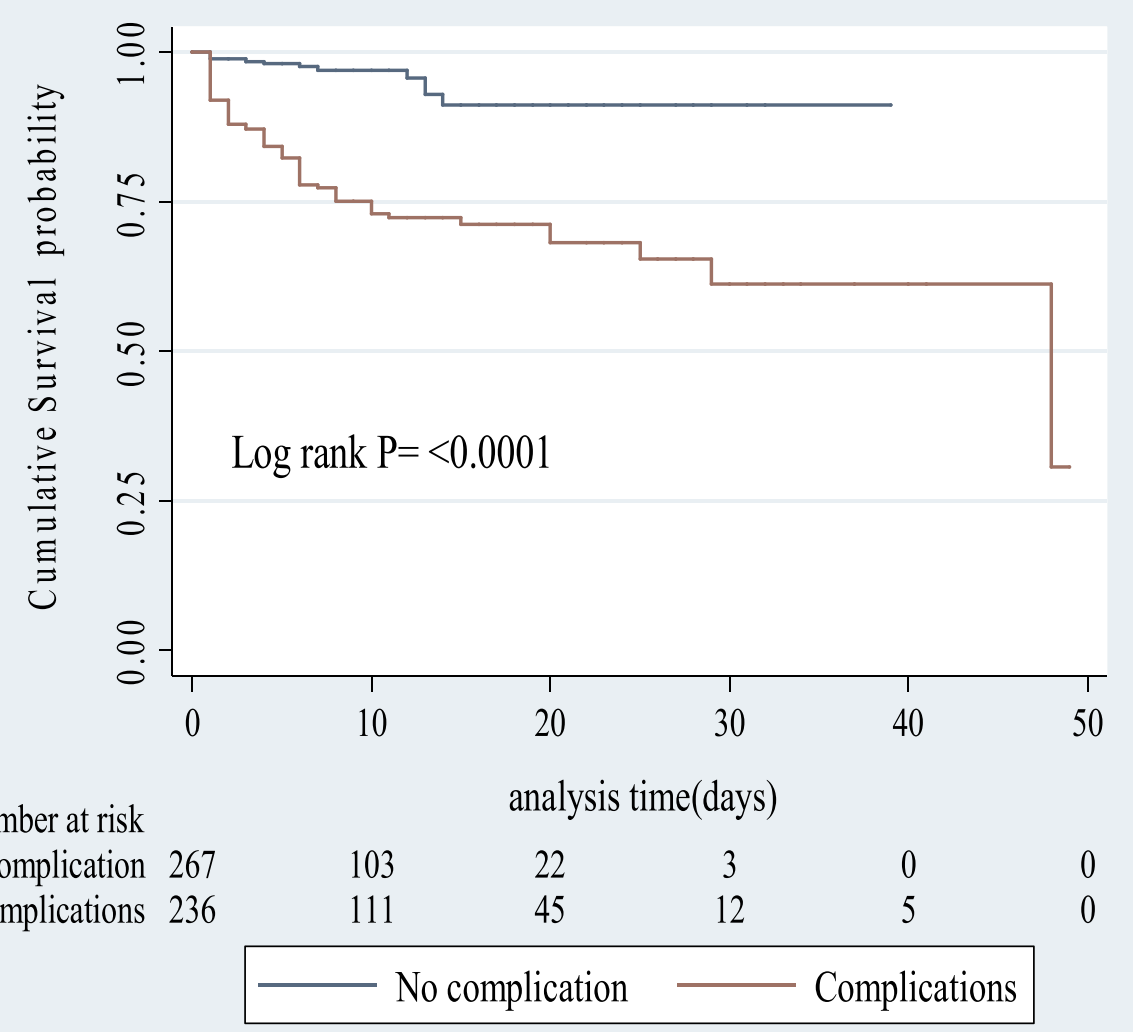

Figure 3 Kaplan-Meier survival curve based on the development of stroke complications among first ever-adult stroke patients admitted in Ayder comprehensive specialized hospital, Northern Ethiopia, 2012-2019.

patients had a $1 \%$ lower hazard of death as compared to non-hypertensive adult stroke patients. These findings were in contradiction with the study done in Saudi Arabia, ${ }^{1}$ whereby hypertensive patients had a $77 \%$ higher hazard of death as compared to non-hypertensive adult stroke patients. This might be due to differences in sample size, follow up period, and the proportion of hypertensive and non-hypertensive patients. In our setup hypertensive patients are somehow better resourced in terms of knowledge on their condition and are relatively better close to medical care than non-hypertensive patients.

We have found that hemorrhagic stroke was the second most common type of stroke identified among $41.55 \%$ of stroke cases which is in contrast to the study done in Addis Ababa. ${ }^{12}$ This finding is three to four times higher than the studies done in western countries. ${ }^{22}$ Hemorrhagic stroke accounts for only $10-15 \%$ of stroke cases, the possible explanations could be due to the high magnitude of hypertension in Africa and the majority of patients were not adherent to their respective anti-hypertensive medications, in our study (72.4\%) all of which contribute to the high magnitude of hemorrhagic stroke.

In agreement with our findings, studies conducted in Hawassa $^{3}$ and the University of Gondar, ${ }^{23}$ found that the cardio-embolic sub-type of ischemic stroke was the most common identified, indicating the dominance of the cardiac causes of ischemic stroke. There was no significant difference in the survival time among different types of stroke; the hazard of death among hemorrhagic stroke patients was $29 \%$ lower than patients who had an ischemic stroke. Similarly, the hazard of death among patients who had subarachnoid hemorrhage was $17 \%$ lower than patients who had an ischemic stroke after adjusting for the effect of age, stroke severity, and presence of stroke complications. Our finding was in line with the study done in the Netherlands. ${ }^{24}$

In our study, admission GCS score was the independent predictor of patient survival, patients who had a GCS score of 3-8 had ten times higher hazard of death as compared to those having a GCS score of 13-15. This 


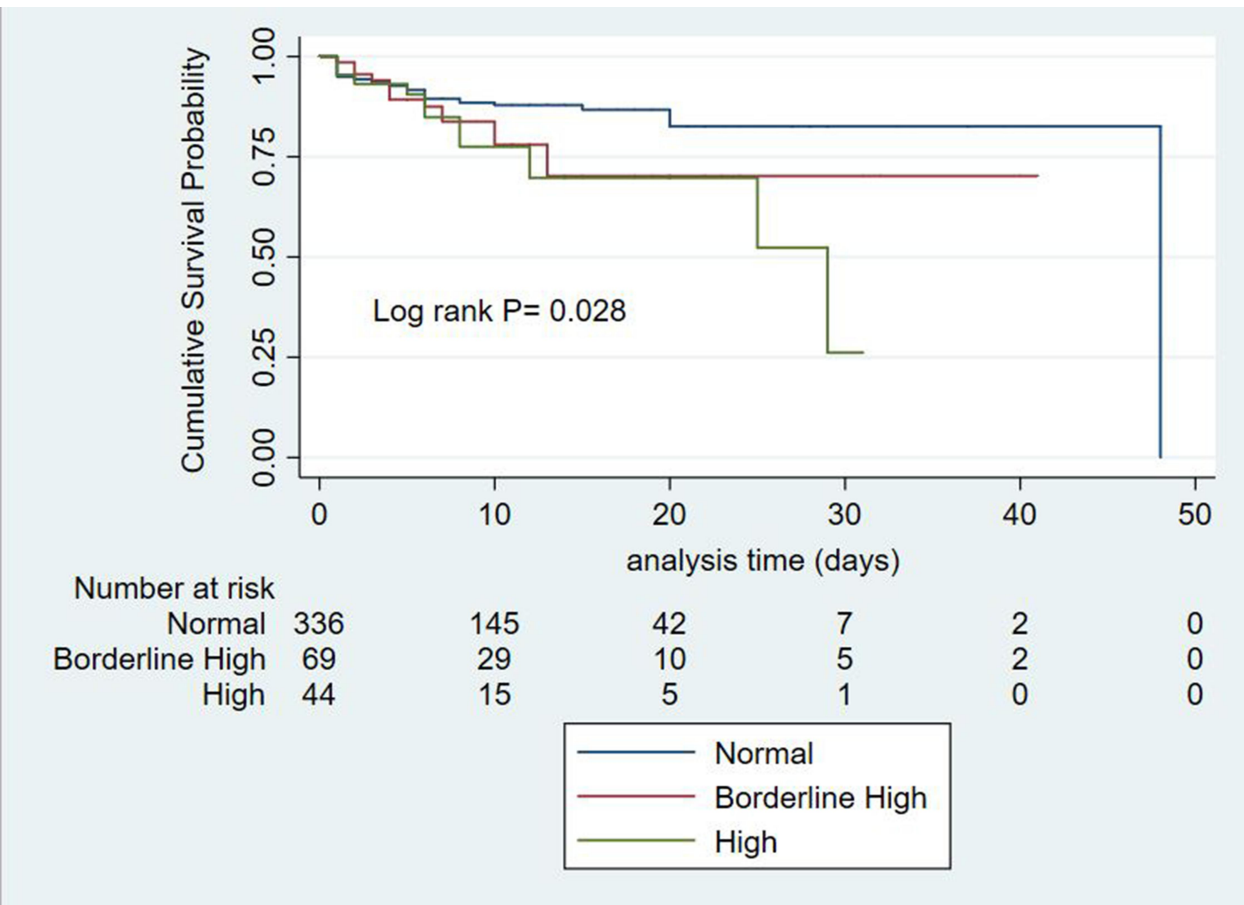

Figure 4 Kaplan-Meier survival curve based on total cholesterol level among first ever-adult stroke patients admitted in Ayder comprehensive specialized hospital, Northern Ethiopia, 2012-2019.

was in line with the study done in Saudi Arabia, ${ }^{1}$ where an altered level of consciousness at presentation had a significantly higher hazard of intra-hospital mortality. Similarly, a study conducted in south London, ${ }^{2}$ found two times the higher hazard of death among patients who had moderate to severe brain injury as compared to alert patients. The possible explanation could be comatose patients had a higher probability of developing acute phase neuro-medical stroke complications, which can predispose them to a higher hazard of death. This finding had a clinical significance during patient management, as it affects the length of stay, the functional outcome of the patient, and overall costs of stroke treatment.

We found that at any particular point in time, the hazard of death among adult stroke patients who had any of the neuro-medical stroke complications was seven times higher than those who had no complications, after adjusting for potential confounders. This finding was in line with the studies done in Italy, ${ }^{25}$ Taiwan, ${ }^{26}$ Saudi Arabia, ${ }^{1}$ this can be explained by the effect of stroke-related depressed immunity; depressed gag-reflex, and delayed mobilization of admitted patients. Early management of complications along with early mobilization and rehabilitation of patients, could significantly lower the incidence of complications, shortens the length of hospital stay and disability after the onset of stroke symptoms.

Adult stroke patients who had a total cholesterol level of borderline high had almost four times the higher hazard of death as compared to patients who had normal total cholesterol levels. A non-significant difference in the hazard of death observed between patients who had high and normal total cholesterol levels, despite having a 57\% higher hazard of death among patients who had a high total cholesterol level. This was different from the study conducted in Sweden, ${ }^{27}$ a high total cholesterol level was an independent predictor of improved long-term survival of ischemic stroke patients. This improved survival among high cholesterol patients created a sense of obesity paradox.

This was the first local study, which tried to determine the survival of stroke patients according to hypertension status by following the minimum gold standard recommendations of Epidemiologic stroke study, ${ }^{5}$ and reporting of quality survival analysis data. ${ }^{28}$ We separately reported the number of first-ever and recurrent cases, we had used only confirmed stroke cases, World Health Organization clinical case definition of stroke, stroke type and sub-types along with the adjusted estimate of predictor variables. 
Table 5 Bivariate and Adjusted Predictors of Mortality Among First-Ever Adult Stroke Patients Admitted in Ayder Comprehensive Specialized Hospital, Northern Ethiopia, 2012-2019

\begin{tabular}{|c|c|c|c|c|c|c|c|c|}
\hline \multicolumn{2}{|l|}{ Covariates } & \multicolumn{2}{|c|}{ Survival Status } & \multirow{3}{*}{$\begin{array}{l}\text { CHR } \\
\text { I (base) }\end{array}$} & \multirow[t]{3}{*}{ P-value } & \multirow[t]{3}{*}{ AHR } & \multirow[t]{3}{*}{$95 \% \mathrm{Cl}$} & \multirow[t]{3}{*}{ P-value } \\
\hline & & \multirow{7}{*}{$\begin{array}{l}\text { Dead (\%) } \\
13(2.6) \\
10(2) \\
24(4.8) \\
17(3.4) \\
7(1.4) \\
4(0.8)\end{array}$} & \multirow{2}{*}{\begin{tabular}{|l|} 
Censored (\%) \\
$61(12.1)$
\end{tabular}} & & & & & \\
\hline Age (in years) & & & & & & & & \\
\hline & $45-54$ & & $44(8.7)$ & 1.12 & 0.79 & 1.05 & $0.15,7.4 \mid$ & 0.96 \\
\hline & $55-64$ & & $75(14.9)$ & 1.51 & 0.24 & 1.41 & $0.25,8.04$ & 0.70 \\
\hline & $65-74$ & & $115(22.8)$ & 0.83 & 0.60 & 1.74 & $0.34,8.91$ & 0.51 \\
\hline & $75-84$ & & $95(18.9)$ & 0.41 & 0.06 & 0.12 & $0.01,1.69$ & 0.12 \\
\hline & $\geq 85$ & & $38(7.6)$ & 0.68 & 0.5 & 0.67 & $0.05,8.64$ & 0.76 \\
\hline \multirow[t]{2}{*}{ Sex } & Male & $39(7.8)$ & $213(42.3)$ & \multicolumn{5}{|c|}{ I(base) } \\
\hline & Female & $36(7.2)$ & $215(42.7)$ & 0.91 & 0.7 & & & \\
\hline \multirow[t]{2}{*}{ Residence $(n=487)$} & Urban & $5 I(10.5)$ & $234(48)$ & \multicolumn{5}{|c|}{ I(base) } \\
\hline & Rural & $22(4.5)$ & $180(37)$ & 0.6 & 0.04 & 0.82 & $0.31,2.13$ & 0.68 \\
\hline \multirow[t]{2}{*}{ Ethnicity $(n=472)$} & Tigrian & $67(14.2)$ & $373(79.1)$ & \multicolumn{5}{|c|}{ I(base) } \\
\hline & Non-Tigrian & $4(0.8)$ & $28(5.9)$ & 0.74 & 0.56 & & & \\
\hline \multirow[t]{2}{*}{ Hypertension } & No & $24(4.8)$ & $156(31)$ & \multicolumn{5}{|c|}{ I(base) } \\
\hline & Yes & $5 I(10.1)$ & $272(54.1)$ & 1.17 & $0.52^{\pi}$ & 2.13 & $0.66,6.81$ & 0.2 \\
\hline \multirow[t]{3}{*}{ Type of stroke } & Ischemic & $35(6.9)$ & $250(49.7)$ & \multicolumn{5}{|c|}{ I(base) } \\
\hline & Hemorrhagic & $37(7.4)$ & $172(34.2)$ & 1.47 & 0.11 & 0.71 & $0.26,1.96$ & 0.51 \\
\hline & $\mathrm{SAH}$ & $3(0.6)$ & $6(1.2)$ & 3.32 & 0.05 & 0.83 & $0.08,8.16$ & 0.87 \\
\hline \multirow[t]{3}{*}{ Sub-type of IS $(n=152)$} & SAO & $9(5.9)$ & $53(34.9)$ & \multicolumn{5}{|c|}{ I(base) } \\
\hline & CE & $6(3.9)$ & $63(4 \mid .5)$ & 0.7 & 0.51 & & & \\
\hline & LAA & $4(2.6)$ & $17(11.2)$ & 1.3 & 0.67 & & & \\
\hline \multirow[t]{2}{*}{ Causes of HS $(n=183)$} & Hypertension & $30(16.4)$ & $148(80.9)$ & \multicolumn{5}{|c|}{ I(base) } \\
\hline & Non-hypertension & $3(1.6)$ & $2(I . I)$ & 4.45 & 0.01 & & & \\
\hline \multirow[t]{2}{*}{ Duration of symptoms } & $<6$ & $4(0.8)$ & $16(3.2)$ & \multicolumn{5}{|c|}{ I(base) } \\
\hline & $\geq 6$ & $7 I(14.1)$ & $4 \mid 2(81.9)$ & 0.63 & 0.37 & & & \\
\hline \multirow[t]{3}{*}{ GCS at admission } & $13-15$ & $9(1.8)$ & $218(43.4)$ & I (base) & & & & \\
\hline & $3-8$ & $48(9.5)$ & $45(8.9)$ & 16.55 & $<0.001$ & 10.12 & $2.58,40.68$ & $0.001 *$ \\
\hline & $9-12$ & $18(3.6)$ & 165(32.8) & 2.45 & 0.03 & 1.75 & $0.44,7.3$ & 0.44 \\
\hline Stroke complications & No & $\mathrm{II}(2.2)$ & $256(50.9)$ & I (base) & & & & \\
\hline & Yes & $64(12.7)$ & $172(34.2)$ & 6.3 & $<0.001$ & 7.23 & $1.86,28.26$ & $0.004^{*}$ \\
\hline Total cholesterol $(n=449)$ & Normal & $40(8.9)$ & $296(65.9)$ & I (base) & & & & \\
\hline & Borderline & $14(3.1)$ & $55(12.3)$ & 1.71 & 0.09 & 3.57 & I.I5, II.I & $0.03 *$ \\
\hline & High & $\mathrm{II}(2.4)$ & $33(7.4)$ & 2.2 & 0.02 & 1.57 & $0.31,7.96$ & 0.58 \\
\hline Platelet count (cells $/ \mathrm{mm}^{3}$ ) & Normal & $57(\mid 1.3)$ & $352(70)$ & I(base) & & & & \\
\hline & $<150,000$ & $\mathrm{II}(2.2)$ & $50(9.9)$ & 1.29 & 0.44 & 1.52 & $0.39,5.83$ & 0.55 \\
\hline & $>450,000$ & $7(1.4)$ & $26(5.2)$ & 1.63 & 0.22 & 1.07 & $0.13,9.15$ & 0.95 \\
\hline
\end{tabular}

(Continued) 
Table 5 (Continued).

\begin{tabular}{|c|c|c|c|c|c|c|c|c|}
\hline \multicolumn{2}{|l|}{ Covariates } & \multicolumn{2}{|c|}{ Survival Status } & \multirow[t]{2}{*}{ CHR } & \multirow[t]{2}{*}{ P-value } & \multirow[t]{2}{*}{ AHR } & \multirow[t]{2}{*}{$95 \% \mathrm{Cl}$} & \multirow[t]{2}{*}{ P-value } \\
\hline & & Dead (\%) & Censored (\%) & & & & & \\
\hline \multirow[t]{2}{*}{ Creatinine level $(n=491)$} & $\leq 1.6$ & $64(13)$ & $396(80.7)$ & \multicolumn{5}{|c|}{ I(base) } \\
\hline & $>1.6$ & $8(1.6)$ & $23(4.7)$ & 1.82 & 0.11 & 0.25 & $0.02,2.49$ & 0.24 \\
\hline
\end{tabular}

Notes: "This variable was significant in the previous study conducted in Saudi Arabiya, we included in the final model even though (P >0.25), *Shows significant difference at $\mathrm{P}<0.05$, ${ }^{\ddagger} \mathrm{P}$-value of Schoenfeld residuals for assessing Cox proportional hazards assumption.

Abbreviations: AHR, adjusted hazard ratio; CE, cardio-embolic; CHR, crude hazard ratio; Cl, confidence interval; GCS, Glasgow Coma Scale; HS, hemorrhagic stroke; LAA, large artery occlusion; SAH, subarachnoid hemorrhage; SAO, small artery occlusion.

The cohort groups were also comparable in most of their baseline characteristics.

The result of this study was not without limitations. First, the study was limited to adult stroke patients who present to the hospital, we cannot rule out potential selection bias (referral bias) for those who died out of the hospital. There was also a significant missing of sociodemographic variables; we excluded them from the Cox regression model, which might affect the adjusted estimates of covariates. We studied all-cause mortalities; we were not able to determine the exact causes of death for each admitted patient, which would imply patient management, by acknowledging these potential limitations we hope that this finding can serve as baseline information for further research.

\section{Conclusions}

We have found that there was no statistically significant difference in survival time between hypertensive and nonhypertensive first-ever adult stroke patients. The exposure status does not matter for patient survival rather; Glasgow Coma Scale at admission, presence of stroke complications, and borderline high total cholesterol level were the independent predictors of patient mortality.

\section{Data Sharing Statement}

The datasets generated and analyzed during the current study are available from the corresponding author on a reasonable request.

\section{Ethics Approval and Informed Consent}

Ethical approval was obtained from Mekelle University, Health Research Ethics Review Committee (ERC 1220/ 2019). The data collected from the medical records were handled with strong confidentiality, neither the case records nor the data extracted were used for any other purpose and all the collected patient information was stored anonymously. The study was conducted following the Declaration of Helsinki.

\section{Author Contributions}

All authors made substantial contributions to conception and design, acquisition of data, or analysis and interpretation of data; took part in drafting the article or revising it critically for important intellectual content; gave final approval of the version to be published; and agree to be accountable for all aspects of the work.

\section{Disclosure}

The authors report no conflicts of interest in this work.

\section{References}

1. Alhazzani AA, Mahfouz AA, Abolyazid AY, et al. In-hospital stroke mortality: rates and determinants in Southwestern Saudi Arabia. Int J Environ Res Public Health. 2018;15(1):927-937. doi:10.3390/ ijerph15050927

2. Wang Y, Rudd AG, Wolfe CD. Trends and survival between ethnic groups after stroke: the South London stroke register. Stroke. 2013;44 (1): $1-6$.

3. Deresse B, Shaweno D. Epidemiology and in-hospital outcome of stroke in South Ethiopia. J Neurol Sci. 2015;xxx (1):xxx-xxx.

4. World health rankings. Ethiopia: stroke [internet]. 2017 [cited September 12, 2018]. Available from: www.worldlifeexpectancy. com/ethiopia-stroke. Accessed September 16, 2020.

5. Adeloye D. An estimate of the incidence and prevalence of stroke in Africa: a systematic review and meta-analysis. PLoS One. 2014;9(6): e100724.

6. GBD 2017 Disease and Injury Incidence and Prevalence Collaborators. Global, regional, and national incidence, prevalence, and years lived with disability for 354 diseases and injuries for 195 countries and territories, 1990-2017: a systematic analysis for the Global Burden of Disease Study 2017. Lancet. 2018;390(1):1789-1858.

7. World Health Organization. The top 10 causes of death [Internet]. 2018 [cited December 5, 2018]. Available from: http://www.who.int/ news-room/fact-sheets/detail/the-top-10-causes-of-death. Accessed September 16, 2020. 
8. Stroke Association. Together We Can Conquer Stroke: Stroke Association Strategy 2015 to 2018. London, United Kingdom; 2015:1-24.

9. Strong K, Mathers C, Bonita R. Preventing stroke: saving lives around the world. Lancet Neurol. 2007;6(2):182-187.

10. Mekelle University. Ayder comprehensive specialized hospital [internet]. [cited August 11, 2018]. Available from: http://www.mu. edu.et/chs/index.php/15-referral-hospital/3-the-ayder-referralhospital. Accessed September 16, 2020.

11. Center for disease control and prevention. Epi Info, a Database, and Statistics Program for Public Health Professionals. Atlanta, Georgia, USA: Center for disease control and prevention; 2018.

12. Gedefa B, Menna T, Berhe T, Abera H. Assessment of risk factors and treatment outcome of stroke admissions at St. Paul's Teaching Hospital, Addis Ababa, Ethiopia. J Neurol Neurophysiol. 2017;8 (3):431-437. doi:10.4172/2155-9562.1000431

13. World Health Organization. WHO STEPS Stroke Manual Version 1.2: The WHO STEPwise Approach to Stroke Surveillance. Geneva, Switzerland: World Health Organization; 2006.

14. Nkoke C, Lekoubou A, Balti E, Kengne AP. Stroke mortality and its determinants in a resource-limited setting: a prospective cohort study in Yaounde, Cameroon. J Neurol Sci. 2015;358(1-2):113-117. doi:10.1016/j.jns.2015.08.033

15. Hoffmeister L, Lavados PM, Murta-Nascimento C, Araujo M, Olavarría VV, Castells X. Short- and long-term survival after stroke in hospitalized patients in Chile: a nationwide 5-year study. J Stroke Cerebrovasc Dis. 2013;22(8):e463-e469. doi:10.1016/j.jstrokecerebrovasdis.2013.05.005

16. Alberti KG, Zimmet PZ. Definition, diagnosis, and classification of diabetes mellitus and its complications, part 1: diagnosis and classification of diabetes mellitus provisional report of a WHO consultation. Diabet Med. 1998;15(7):539-553. doi:10.1002/(SICI) 1096-9136(199807)15:7<539::AID-DIA668>3.0.CO;2-S

17. Cocho D, Yarleque S, Boltes A, et al. Clinical outcome of ischemic stroke in old patients versus oldest-old. J Stroke Cerebrovasc Dis. 2018;27 (12):3657-3661. doi:10.1016/j.jstrokecerebrovasdis.2018.08.041
18. Mehta R, Chinthapalli K. Glasgow coma scale explained. BMJ. 2019;365:1296-1303. doi:10.1136/bmj.11296

19. StataCorp. Stata Statistical Software: Release 14. College Station, Texas, USA: StataCorp LLC; 2017.

20. Hosmer DW, Lemeshow S, May S. Applied Survival Analysis: Regression Modeling of Time - To- Event Data. Second ed. Massachusetts, USA: A Wiley inter science publication; 2008.

21. Kaduka L, Muniu E, Oduor C, et al. Stroke mortality in Kenya's Public Tertiary Hospitals: a prospective Facility-Based Study. Cerebrovasc Extra. 2018;8(1):70-79. doi:10.1159/000488205

22. Johnson W, Onuma O, Owolabi M, Sachdev S. Stroke: a global response is needed. Bull World Health Organ. 2016;94(1):634634A. doi:10.2471/BLT.16.181636

23. Gebreyohannes EA, Bhagavathula AS, Abebe TB, Seid MA, Haile KT. In-hospital mortality among ischemic stroke patients in Gondar University Hospital: a Retrospective Cohort Study. Stroke Res Treat. 2019;2019(1):1-7. doi:10.1155/2019/7275063

24. Rutten-Jacobs LC, Arntz RM, Maaijwee NA, et al. Long-term mortality after stroke among adults aged 18 to 50 years. J Am Med Assoc. 2013;309(11):1136-1144.

25. Carlo AD, Lamassa M, Franceschini M, Bovis F, Cecconi L, Pournajaf S. Impact of acute-phase complications and interventions on 6-month survival after stroke. A prospective observational study. PLoS One. 2018;13(3):e0194786.

26. Chen HF, Li CY, Lee SP, Kwok YT, Chu YT. Improving the one-year mortality of stroke patients: an 18-year observation in a Teaching Hospital. Tohoku J Exp Med. 2014;232:1. doi:10.1620/tjem.232.47

27. Markaki I, Nilsson U, Kostulas K, Sjostrand C. High cholesterol levels are associated with improved long-term survival after acute ischemic stroke. J Stroke Cerebrovasc Dis. 2014;23(1):e47-e53.

28. Zhu X, Zhou X, Zhang Y, Sun X, Liu H, Zhang Y. Reporting and methodological quality of survival analysis in articles published in Chinese oncology journals. Medicine (Baltimore). 2017;96(50): e9204. doi:10.1097/MD.0000000000009204
Vascular Health and Risk Management

\section{Publish your work in this journal}

Vascular Health and Risk Management is an international, peerreviewed journal of therapeutics and risk management, focusing on concise rapid reporting of clinical studies on the processes involved in the maintenance of vascular health; the monitoring, prevention and treatment of vascular disease and its sequelae; and the involvement of metabolic disorders, particularly diabetes. This journal is indexed on PubMed Central and MedLine. The manuscript management system is completely online and includes a very quick and fair peerreview system, which is all easy to use. Visit http://www.dovepress. com/testimonials.php to read real quotes from published authors. 